\title{
A population study on perinatal psychological distress in Mexican fathers
}

\author{
Ma. Asunción Lara, 'Shoshana Berenzon, 'Lourdes Nieto,' Laura Navarrete, 'Clara Fleiz, ${ }^{1}$ Marycarmen Bustos, \\ Jorge Villatoro
}

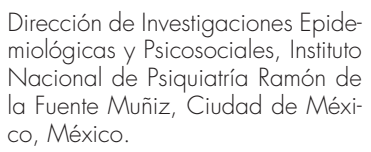

Dirección de Investigaciones Epidemiológicas y Psicosociales, Instituto Nacional de Psiquiatría Ramón de la Fuente Muñiz, Ciudad de México, México.

\section{Correspondence:}

Ma. Asunción Lara

Dirección de Investigaciones

Epidemiológicas y Psicosociales,

Instituto Nacional de Psiquiatría

Ramón de la Fuente Muñiz.

Calzada México-Xochimilco 101

San Lorenzo Huipulco,

14370, Tlalpan,

Ciudad de México México.

Phone: $554160-5170$

Fax: $555513-3446$

Email: laracan@imp.edu.mx

Received: 6 November 2020

Accepted: 4 May 2021

\section{Citation:}

Lara, M. A., Berenzon, S. Nieto, L., Navarrete, L., Fleiz, C., Bustos, M. \& Villatoro, J. (2021). A population study on perinatal psychological distress in Mexican fathers. Salud Mental, 44(6), 267-275.

\section{DOI: $10.17711 /$ SM.0185-3325.2021.035}

\begin{abstract}
Introduction. The transition to parenthood can be a source of stress for fathers and, in some cases, it can be accompanied by emotional distress. This aspect has been neglected in Mexican research. Objective. To estimate the prevalence of emotional distress and the sociodemographic factors associated with it in Mexican fathers. Method. Cross-sectional study. A subsample of 997 fathers, over 18 years of age, was taken from the data of a national survey, whose partners were pregnant or had given birth in the last six months. The Kessler Emotional Distress Scale (K6) was used. Results. About $25 \%$ of the fathers experienced moderate emotional distress during their partner's pregnancy and $29.5 \%$ during the postpartum period; $1.0 \%$ and $1.9 \%$ showed serious emotional distress in those periods, respectively. Being between 18 and 29 years old (PR $=.10 ; \mathrm{Cl}$ $[.01, .79])$, having lower educational attainment $(\mathrm{PR}=5.59 ; \mathrm{Cl}[1.19,26.21])$, and going through postpartum $(P R=4.11 ; \mathrm{Cl}[1.00,16.78])$ were at higher risks for severe emotional distress; having one or two children (PR $=.16 ; \mathrm{Cl}[.05, .55])$ or more than three $(\mathrm{PR}=.08 ; \mathrm{Cl}[.01, .44])$ was a higher risk than being a first-time father. Discussion and conclusion. It is necessary to continue studying paternal perinatal mental health due to the impact it has on the mother and the infant, and to design tailored interventions. Parental emotional distress needs to be better understood considering recent changes in the paternal role in developing countries.
\end{abstract}

Keywords: Psychological distress, fathers, peripartum period, mental health, risk factors.

\section{RESUMEN}

Introducción. La transición a la paternidad puede ser una fuente de estrés para los padres, y en algunos casos, acompañarse de malestar emocional. Este aspecto se ha descuidado en la investigación mexicana. Objetivo. Estimar la prevalencia del malestar emocional y los factores sociodemográficos asociados al mismo en padres mexicanos. Método. Estudio transversal. Se tomó una submuestra de 997 padres, mayores de 18 años, de los datos de una encuesta nacional, cuyas parejas estaban embarazadas o habían dado a luz en los últimos seis meses. Se utilizó la Escala de Malestar Emocional de Kessler (K6). Resultados. Cerca de $25 \%$ de los padres experimentó malestar emocional moderado durante el embarazo de su pareja y $29.5 \%$, durante el posparto; $1.0 \%$ y $1.9 \%$ mostró malestar emocional grave en esos periodos, respectivamente. Tener entre 18 y 29 años (PR = .10; IC [.01, .79]), menor escolaridad (PR = 5.59; IC [1.19, 26.21]) y estar en el posparto $(P R=4.11$; IC $[1.00,16.78])$ fueron mayores riesgos de malestar emocional grave; tener uno o dos hijos $(P R=.16$; IC $[.05, .55])$ o más de tres $(P R=.08$; IC $[.01, .44])$ fueron mayor riesgo que ser padre por primera vez. Discusión y conclusión. Es necesario continuar estudiando la salud mental perinatal paterna debido al impacto que tiene sobre la madre y el infante y para diseñar estrategias de intervención psicológica ad hoc. El malestar emocional de los padres debe entenderse mejor, a la luz de los cambios recientes en el papel paterno en países en desarrollo.

Palabras clave: Malestar emocional, padres, periodo perinatal, salud mental, factores de riesgo. 


\section{INTRODUCTION}

The period of transition to fatherhood is marked by significant changes that constitute a source of stress for men. These are often accompanied by depression, psychological distress, and anxiety (Glasser \& Lerner-Geva, 2019; Philpott, Leahy-Warren, FitzGerald, \& Savage, 2017; Chhabra, McDermott, \& Li, 2020). The study of paternal perinatal mental health, which begins when a man's partner becomes pregnant and lasts through the first year after birth, has received much less attention than that of mothers (Chhabra et al., 2020).

There is ample evidence that perinatal depression and anxiety in mothers have negative consequences on the family, the fetus, and the baby (Falah-Hassani, Shiri, \& Dennis, 2017). Likewise, maladaptive responses in perinatal fathers have an impact on the family and the development of the infant (Chhabra et al., 2020; McCoy, 2012; Giallo, Cooklin, Wade, D'Esposito, \& Nicholson, 2014). The study of paternal mental health is therefore very much needed as a first step to prevent its negative consequences.

Perinatal depression in fathers has been the main research focus with fewer studies addressing psychological distress. Psychological distress extends beyond the restrictive symptoms associated with depression to include anxiety and stress (Schulz, 2016). Psychological or emotional distress is also often related to coping, with psychological distress generally involving a maladaptive psychological response and a range of symptoms such as anxiety, stress, and depression, arising from a variety of stressors (Button, Thornton, Lee, Shakespeare, \& Ayers, 2017). Measurement of non-specific psychological distress is important to cover the whole spectrum of psychological and behavioral responses in a clinically meaningful way (Skari et al., 2002), as well as to distinguish community cases based on severity rather than purely on diagnosis (Kessler et al., 2002).

Mild to severe psychological distress has been estimated in perinatal fathers, ranging from $6.7 \%$ to $12.5 \%$ (Depression, Anxiety, and Stress Scales) (DASS-42) ${ }^{1}$ (Lovibond \& Lovibond, 1995) from week six to 36 during pregnancy and from $7.8 \%$ to $11.1 \%$ during the postpartum period (Schulz, 2016), with clinically important psychological distress at $13 \%$ (General Health Questionnaire) (GHQ) ${ }^{2}$ (Goldberg, 1978) and severely intrusive stress symptoms (Impact of

\footnotetext{
1 The Depression, Anxiety and Stress Scales (DASS) aimed at evaluating the presence of the negative effect of depression and anxiety and achieving maximum discrimination between these conditions, whose clinical overlap has been reported by clinicians and researchers (Lovibond \& Lovibond, 1995). The scales include essential symptoms for each condition and exclude those that may be present in both disorders. During the successive factorial analyzes, the stress factor emerged, which brings together symptoms related to difficulty in relaxing, nervous tension, irritability, and agitation (Lovibond \& Lovibond, 1995).

2 The General Health Questionnaire is a self-administered questionnaire aimed at detecting individuals with a diagnosable psychiatric disorder (Goldberg \& Hillier, 1979). The 12-Item General Health Questionnaire (GHQ-12) is the most extensively used screening instrument for common mental disorders, in addition to being a more general measure of psychiatric well-being.
}

Event Scale) in 2\% of fathers (Skari et al., 2002). The prevalence of paternal depression during the perinatal period estimated in meta-analyses ranges from $8.4 \%$ (Cameron, Sedov, \& Tomfohr-Madsen, 2016) to 10.4\% (Paulson \& Bazemore, 2010) and from $2.3 \%$ to $8.4 \%$ (Glasser \& Lerner-Geva, 2019), and in a systematic review, paternal perinatal anxiety affects between, $2 \%$ and $18 \%$ of fathers (Leach, Poyser, Cooklin, \& Giallo, 2016). Paternal perinatal depression may be experienced together with feelings of loss of control and impotence in face of the demands of infant care and the sudden changes in the dynamics of the couple relationship. In some cases, fathers also express feelings of guilt at spending more time at work and being unable to be more involved in the infant's care (McCoy, 2012).

Compared to mothers (37\%), fathers experience psychological distress less frequently $(13 \%)$ in the postpartum period, as measured by the GHQ (Skari et al., 2002). This finding has also been reported by other authors (Vismara et al., 2016).

A systematic review finds that risk factors for men's psychological distress during the perinatal period have been related to low relationship satisfaction, financial burden, and poor job quality (Leach et al., 2016). These authors remark that distress at this time can also result from extreme fatigue, poor partner and/or infant health, and feelings of inadequacy as a parent. For other mental health problems, Philpott, Savage, Leahy-Warren, and FitzGerald's (2020) narrative review identified several sociodemographic variables that contribute to depression in perinatal fathers, including paternal age, lower educational attainment, parity, unplanned pregnancy, and maternal depression.

Fathers share with mothers some risk factors for psychological distress. A few days after birth, being a single parent increases the risk of distress (GHQ) in both parents; but, for mothers, current birth complications, multiparity, and previous traumatic birth are additionally important risk for distress. At six weeks after birth, risk factors for distress for mothers and fathers are very different: anxiety is relevant for mothers and having previous children, for fathers (Skari et al., 2002).

Paternal mental health has scarcely been addressed in Latin America. The only published study on Mexican fathers identified $10 \%$ with a major depressive episode during pregnancy and $4.6 \%$ and $3.8 \%$ in the fourth and eighth weeks postpartum, respectively (Ocampo, Heinze, \& Ontiveros, 2007). In Brazilian fathers, paternal clinical depression is reported in $4.5 \%$ between weeks four and eigth postpartum (Pinheiro et al., 2011) while depressive symptoms are reported in $11.9 \%$, from week six to 12 (Pinheiro et al., 2006).

In recent decades, men have become increasingly willing and capable of cooperating with their children, but it would appear they have only recently assumed significant levels of responsibility despite that the new ideals of 'in- 
volved' fatherhood are still highly debated (Wall \& Arnold, 2007). In this respect, the authors argue that to the extent that involvement exists, it still occurs within the framework of fathers as part-time, secondary parents, and their relationship with children remains less important than mothers.

Regarding Mexican fathers, they seem to be redefining their concepts about their parental role through their attitudes and fathering practices, but only recently have some fathers begun to attempt to reconcile work with raising and caring for their offspring (Ramírez Rodríguez \& Cervantes Ríos, 2013). However, this change from the traditional role of provider to include the care of their children too is not easy, due to the absence of paternity leaves and the lack of well-payed part-time jobs that include social benefits, generating psychological distress (Tena, 2014).

Paternal psychological distress has negative consequences for infants associated with motor and socioemotional development problems in one-year-olds. A longitudinal study of over 2,000 fathers reported that fathers with high distress in the postnatal period were significantly more likely to parent with high levels of hostility, which affects the emotional and behavioral areas of their children from four to five years of age (Giallo et al., 2014).

The dearth of studies on perinatal paternal mental health in Latin America, which represent low- and middle-income countries (LMICs), with a predominance of traditional beliefs about fathers' role (Morales, Catalán, \& Pérez, 2018), warrants further research. Accordingly, the aim of the study is to explore the prevalence of psychological distress and the associated sociodemographic factors (age, marital status, occupational status, income, educational attainment, and parity) in Mexican fathers. Based on the previous review, psychological distress is expected to be higher in the postpartum than in pregnancy and that younger parents, unemployed, with lower educational levels and with more children will show higher rates of psychological distress.

The results of this study will contribute to the knowledge of paternal psychological distress in this area and provide evidence of the need for screening and prevention to reduce consequences for the father and improve the mental health of mothers and infants.

\section{METHOD}

\section{Design of the study}

The study was cross-sectional. The data was collected as part of the National Survey on Drug, Alcohol, and Tobacco Use -Spanish acronym ENCODAT- (ENCODAT, 2016). ${ }^{3}$ The main objective of ENCODAT was to estimate the prev-

\footnotetext{
3 For more information on the procedures in the survey, see Methodological summary https://www.gob.mx/cms/uploads/attachment/file/234804/RESUMEN_METODOL_GICO.pdf.
}

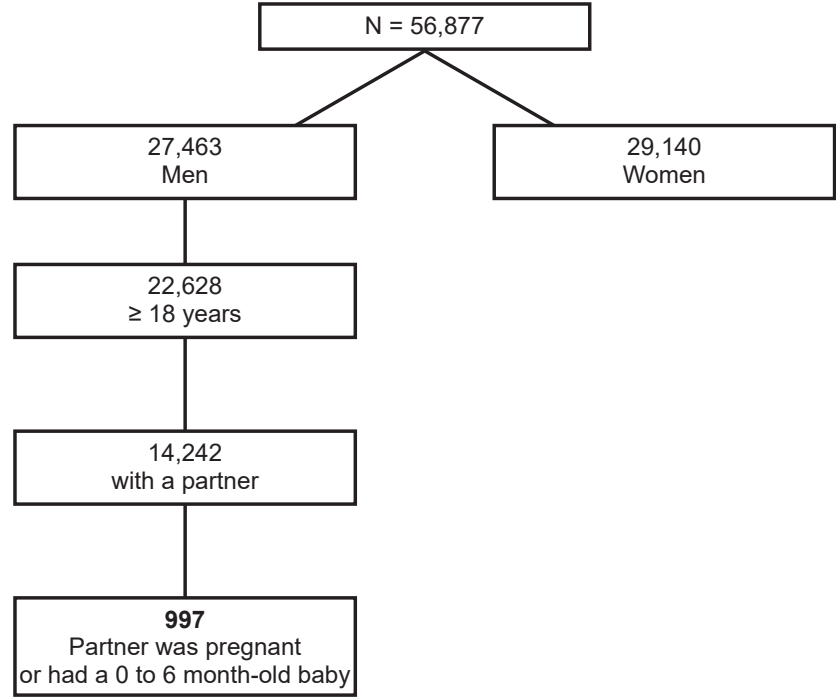

Figure 1. Sample selection flow chart.

alence of tobacco, alcohol, and other drugs use in the population aged 12 to 65 years, as well as assessing consumption trends, antecedents, and determinants of these problems. In addition, other mental health issues of national interest were analyzed, such as suicidal ideation and attempt, partner violence, gambling, and emotional distress.

\section{Participants}

The target population of ENCODAT was people ages 12 to 65 living in the households surveyed. The sample design was probabilistic and stratified by socioeconomic variables, defined by the availability of services in the community and household characteristics. Selection of the sample involved several stages based on the Basic Geostatistical Areas (AGEB's for its acronym in Spanish), ${ }^{4}$ blocks, households, and lastly one person was selected per household together with a teenager ages 12 and 17 if they lived in the selected household. It was possible to conduct more than one interview in each home. The households selected were visited about four times to obtain a response rate of $70 \%$. The sample estimate was 64,000 people. The 2016 ENCODAT had national, regional, and state representation, a total response rate (household + individual) of $73.6 \%$ and a final sample of 56,877 complete interviews $(27,463$ men and 29,414 women), of which 9,563 were adolescents and 47,314 adults.

For the aim of this study, a sample of 997 perinatal fathers (515 during pregnancy and 482 in the postpartum period) was selected based on the following criteria: a) men who reported having a partner; b) were $>18$ years old; and c) whose partner was pregnant or in the first six months postpartum period (Figure 1).

4 AGEBS refer to small territorial areas comprising the municipalities and states of the country. They are generally made up of a set of one to 50 blocks (INEGI, 2010 http://www.beta.inegi.org.mx/contenidos/temas/ mapas/mg/metadatos/manual_cartografia_censal.pdf ). 


\section{Instruments}

ENCODAT comprises several sections. For this study, only the following variables were analyzed.

Sociodemographic data: age, marital status, employment status (unemployment was defined as not having engaged in paid employment in the past 30 days), income, educational attainment, number of children, and perinatal period (pregnancy/postpartum). ${ }^{5}$

Psychological distress. The Kessler Psychological Distress Scale (K6) was used to measure this aspect (Kessler et al., 2002). The six-item scale measures feelings of nervousness, hopelessness, restlessness, depression, uselessness, and overexertion. It provides a measure of the severity of symptoms and general levels of psychological distress. The total scores of the scale range from 0 to 24 points. A standard cut-off score of $\geq 13$ is used to identify people with severe psychological distress, in other words, individuals with a high probability of presenting a diagnosable mental disorder severe enough to cause functional limitations and require treatment (Kessler et al., 2003). A cut-off score of

5 The percentage of the population living in Mexico that do not have Mexican nationality is .04\% (INEGI, 2015). $\geq 5$ indicates moderate psychological distress that remains clinically relevant and therefore requires some form of intervention.

Mexico participated in the international validation of K6 through its application as part of the World Mental Health Survey conducted in 14 countries (Kessler et al., 2010). A factor analysis assessed its internal consistency at the primary care level, yielding a single factor that explained $53.4 \%$ of the total variance with internal consistency of $\alpha=$ .901 (Vargas, Villamil, Rodríguez, Pérez, \& Cortés, 2011).

\section{Procedure}

Data collection was undertaken in various stages. Once a household had been selected, an individual was chosen for interviewing based on a questionnaire. The interview included several sections (e.g., drug and alcohol use, partner violence, harm to others, psychological distress), with only those relevant to the present study being recorded. The field work was supervised by researchers specifically trained in this task. The training of interviewers was carried out from May 16 to 30,2016, while data collection took place June 1 to October 30 of that year.

Table 1

Demographic characteristics of fathers

\begin{tabular}{|c|c|c|c|c|c|c|}
\hline & \multicolumn{3}{|c|}{ Pregnancy } & \multicolumn{3}{|c|}{ Postpartum } \\
\hline & $n=515$ & $N=276,386$ & $\%$ & $n=482$ & $N=258,579$ & $\%$ \\
\hline \multicolumn{7}{|l|}{ Age } \\
\hline $18-29$ years & 254 & 136,292 & 49.3 & 198 & 106,090 & 41.0 \\
\hline $30-39$ years & 148 & 79,632 & 28.7 & 162 & 86,983 & 33.6 \\
\hline $40-49$ years & 78 & 42,131 & 15.2 & 84 & 45,101 & 17.4 \\
\hline $50-65$ years & 35 & 18,601 & 6.7 & 38 & 20,586 & 8.0 \\
\hline \multicolumn{7}{|l|}{ Marital status } \\
\hline Co-habiting & 245 & 131,283 & 47.5 & 219 & 117,653 & 45.5 \\
\hline Married & 270 & 145,103 & 52.5 & 263 & 140,926 & 54.5 \\
\hline \multicolumn{7}{|l|}{ Employed } \\
\hline Yes & 483 & 259,369 & 93.8 & 465 & 24,2799 & 96.5 \\
\hline No & 32 & 17,017 & 6.2 & 17 & 8,961 & 3.5 \\
\hline \multicolumn{7}{|l|}{ Monthly family income } \\
\hline$\leq 4$ minimum wages* & 411 & 220,546 & 79.8 & 341 & 183,125 & 70.7 \\
\hline$\geq 5$ minimum wages & 104 & 55,839 & 20.2 & 141 & 75,634 & 29.3 \\
\hline \multicolumn{7}{|l|}{ Educational attainment } \\
\hline$\leq$ Junior high school & 302 & 162,015 & 58.6 & 298 & 159,948 & 61.8 \\
\hline$\geq$ Senior high school & 213 & 114,370 & 41.4 & 184 & 98,812 & 38.2 \\
\hline \multicolumn{7}{|l|}{ Number of children } \\
\hline 0 & 48 & 25,954 & 12.3 & 40 & 21,616 & 8.5 \\
\hline $1-2$ & 269 & 144,655 & 69.0 & 277 & 148,706 & 58.8 \\
\hline$\geq 3$ & 73 & 39,283 & 18.7 & 154 & 82,916 & 32.7 \\
\hline
\end{tabular}

Note: *Four monthly minimum wages equal $\$ 8,764.00$ Mexican pesos ( $\$ 455.28$ US dollars). 


\section{Statistical analysis}

Data was analyzed with Stata version 13.1 (STATA, 2013), using the complex survey analysis module, svy, which considers the sample design that includes the definition of weight, stratum, and grouping variable to obtain more accurate estimates. Prevalence estimates were obtained for demographic characteristics and psychological distress. In addition, differences in the prevalence of psychological distress by demographic variable were estimated with the adjusted prevalence ratio (PR), based on generalized linear models (GLM) with log link and binomial distribution. For GLMs, 95\% confidence intervals (CI) were estimated.

\section{Ethical considerations}

The ENCODAT 2016 survey protocol was approved by the IRBs of the Ramón de la Fuente Muñiz National Institute of Psychiatry (Instituto Nacional de Psiquiatría Ramón de la Fuente Muñiz, INPRFM) and the National Institute of Public Health (Instituto Nacional de Salud Pública, INSP), which was also involved in the survey. All the participants were read a letter of consent and information was only gathered on those who agreed to participate. The actual analysis was approved by the IRB of the INPRFM (06/18/2018).

\section{RESULTS}

Table 1 shows the demographic characteristics of the sample. As can be seen, participants were mostly young (19-29 years) and over half were married (52.5\% pregnancy and 54.4\% postpartum). Few participants were unemployed (6\% pregnancy and 3\% postpartum). Over half had a monthly family income of $\leq 4$ minimum wages $(79.8 \%$ pregnancy and $70.7 \%$ postpartum) and an educational attainment of $\leq$ Junior high school (58.6\% pregnancy and $61.8 \%$ postpartum). The majority had one or two children (69\% pregnancy and 58.8\% postpartum).
Moderate psychological distress prevalence was $24.9 \%$ (pregnancy) and 29.5\% (postpartum period), with no significant differences being observed between these periods. As for severe psychological distress, $1.0 \%$ presented this condition in pregnancy and $1.9 \%$ in the postpartum period, with no statistically significant differences (Table 2).

Men over 50 years of age (38.4\%) presented moderate emotional distress, as well as married men $(28 \%)$, those with higher income (29.4\%), less educational attainment $(28.8 \%)$, three or more children $(30.7 \%)$, and those whose wife is in the postpartum period (29.5\%) (Table 3). However, the PR-adjusted analysis for moderate psychological distress showed that none of the variables was associated with the criterion variable (Table 3 ).

As for severe psychological distress, men older than 50 years $(3.4 \%)$, more frequently presented severe emotional distress, as well as men without employment (2.4\%), with less educational attainment $(2.2 \%)$, without children $(6.2 \%)$, and those and those with his wife are in postpartum (1.9\%) (Table 4). The PR-adjusted analysis found that fathers aged 40 to 49 were at a lower risk for severe psychological distress than those aged between 18 and 29 $(\mathrm{PR}=.10$; CI $[.01, .79])$; while having lower educational attainment ( $\mathrm{PR}=5.59$; $\mathrm{CI}[1.19,26.21])$ increased the risk of severe psychological distress. Those with one or two children $(\mathrm{PR}=.16$; $\mathrm{CI}[.05, .55])$ or $\geq 3(\mathrm{PR}=.08$; CI $[.01$, .44]) had a lower risk of severe distress than first-time fathers, while postpartum fathers $(\mathrm{PR}=4.11$; CI [1.00, 16.78]) had a higher risk of presenting severe psychological distress than fathers during their partners' pregnancy.

\section{DISCUSSION AND CONCLUSION}

This study found a moderate level of psychological distress in a quarter of prenatal (24.9\%) and postnatal (29.5\%) fathers. These percentages are higher than those reported previously by Schulz (2016), who found rates of $6.7 \%$ to $12.5 \%$ in fathers during pregnancy, and of $7.8 \%$ to $11.1 \%$ during the postpartum period; Skari et al. (2002) observed

Table 2

Prevalence of psychological distress in perinatal fathers

\begin{tabular}{|c|c|c|c|c|c|c|c|c|}
\hline & \multicolumn{3}{|c|}{ Pregnancy } & \multicolumn{3}{|c|}{ Postpartum } & \multirow[b]{2}{*}{$X^{2}$} & \multirow[b]{2}{*}{$p$} \\
\hline & $n=515$ & $N=276,386$ & $\%$ & $n=482$ & $N=258,579$ & $\%$ & & \\
\hline \multicolumn{9}{|c|}{$\begin{array}{l}\text { Moderate Psychological Distress } \\
(\mathrm{K} 6 \leq 5)\end{array}$} \\
\hline Yes & 128 & 68,787 & 24.9 & 142 & 76,417 & 29.5 & 2.6 & .06 \\
\hline No & 387 & 207,598 & 75.1 & 340 & 182,343 & 70.5 & & \\
\hline $\begin{array}{l}\text { Severe Psychological } \\
(K 6 \geq 13)\end{array}$ & & & & & & & & \\
\hline Yes & 5 & 2,920 & 1.0 & 9 & 4,953 & 1.9 & 1.4 & .17 \\
\hline No & 510 & 27,3465 & 99.0 & 473 & 253,806 & 98.1 & & \\
\hline
\end{tabular}


Table 3

Prevalence ratio of moderate psychological distress $(K 6 \geq 5)$ by demographic characteristics

\begin{tabular}{|c|c|c|c|c|c|c|}
\hline & $n=270$ & $n=145,204$ & $\%(95 \% \mathrm{Cl})$ & $P R$ & $95 \% \mathrm{Cl}$ & $p$ \\
\hline \multicolumn{7}{|l|}{ Age } \\
\hline $18-29$ & 116 & 62,150 & $25.7(20.8-31.0)$ & 1 & - & - \\
\hline $30-39$ & 70 & 37,810 & 22.7 (17.8-28.5) & .92 & $.65-1.31$ & .67 \\
\hline $40-49$ & 56 & 30,121 & $34.6(24.7-45-8)$ & 1.19 & $.76-1.84$ & .43 \\
\hline $50-65$ & 28 & 15,123 & $38.4(26.1-52.7)$ & 1.38 & $.85-2.26$ & .18 \\
\hline \multicolumn{7}{|l|}{ Marital status } \\
\hline Married & 149 & 80,007 & $28.0(23.2-33.4)$ & 1 & - & - \\
\hline Co-habiting & 121 & 65,197 & $26.2(21.4-31.4)$ & .89 & $.66-1.20$ & .45 \\
\hline \multicolumn{7}{|l|}{ Employed } \\
\hline Yes & 257 & 138,053 & $27.1(23.6-30.8)$ & 1 & - & - \\
\hline No & 13 & 7,151 & $27.1(16.4-42.2)$ & 1.12 & $.79-2.35$ & .26 \\
\hline \multicolumn{7}{|l|}{ Monthly family income } \\
\hline$\geq 5$ minimum wages & 72 & 38,805 & $29.4(22.3-37.8)$ & 1 & - & - \\
\hline$\leq 4$ minimum wages & 198 & 106,399 & $26.3(22.6-30.4)$ & 1.05 & $.74-1.49$ & .76 \\
\hline \multicolumn{7}{|l|}{ Educational attainment } \\
\hline$\leq$ Junior high school & 172 & 92,783 & $28.8(24.5-33.4)$ & 1 & - & - \\
\hline$\geq$ Senior high school & 98 & 52,421 & 24.7 (19.3-30.6) & 1.07 & $.78-1.45$ & .66 \\
\hline \multicolumn{7}{|l|}{ Number of children } \\
\hline 0 & 30 & 16,263 & $29.2(18.2-43.2)$ & 1 & - & - \\
\hline $1-2$ & 159 & 85,380 & $25.1(20.9-29.8)$ & .90 & $.05-0.55$ & .69 \\
\hline$\geq 3$ & 81 & 45,561 & 30.7 (23.3-39.0) & 1.07 & $.01-0.44$ & .78 \\
\hline \multicolumn{7}{|l|}{ Perinatal period } \\
\hline Pregnancy & 128 & 68,787 & $24.9(20.3-30.0)$ & 1 & - & - \\
\hline Postpartum & 142 & 76,417 & $29.5(24.7-34.8)$ & 1.32 & $.98-1.79$ & .06 \\
\hline
\end{tabular}

rates of $13 \%$ after childbirth. The higher prevalence found among Mexican perinatal fathers may partly be due to the differences in screening methods used, but also to the effect of living conditions on fathers in a developing country, an effect also noted in Mexican women with perinatal depression (Fisher et al., 2012; Lara, Navarrete, \& Nieto, 2016). Populations in lower income countries have limited access to mental health services (Borges et al., 2006), and a high proportion experience poverty, exposing them to an increased risk of disability, where, even in the absence of absolute poverty, social inequalities and relative poverty can lead to stress, which can worsen both mental and physical health and functioning (Banks, Kuper, \& Polack, 2017).

A very small percentage of Mexican fathers reported severe psychological distress (K6 $\geq 13$ ): 1.0\% during pregnancy and $1.9 \%$ in the postpartum period. The only relatively comparable study in this respect is the one by Skari et al. (2002), who found a prevalence of $2 \%$ of postpartum fathers with severe intrusive stress symptoms. Further research is required to confirm the magnitude of severe stress in perinatal Mexican fathers to rule out the fact that this low level is not due to men's tendency to underreport mental health problems (O'Brien et al., 2017), or to mask these symptoms with externalized behavior and disorders such as substance abuse, avoidance behavior, and anger (Addis, 2008; Cochran \& Rabinowitz, 2000).

Age was associated with severe psychological distress and younger fathers were found to be more distressed. Becoming a father before the mid-20s could mean that higher education is postponed because of the need to secure fulltime employment to support one's family. Parental age has been considered a mediating factor for social and psychological dynamics affecting the new parent's emotional well-being (Bergström, 2013). However, in a systematic review, Philpott et al. (2017) found contradictory evidence regarding the contribution of age to stress levels to confirm this finding.

Severe psychological distress in perinatal fathers was also associated with low educational attainment. Despite the lack of evidence on the influence of education on pa- 
Table 4

Prevalence ratio of severe psychological (K6 $\geq 13)$ distress by demographic characteristics

\begin{tabular}{|c|c|c|c|c|c|c|}
\hline & $n=15$ & $N=7,874$ & $\%(95 \% \mathrm{Cl})$ & $P R$ & $95 \% \mathrm{Cl}$ & $p$ \\
\hline \multicolumn{7}{|l|}{$\overline{\text { Age }}$} \\
\hline $18-29$ & 10 & 5,378 & $2.2(1.1-4.3)$ & 1 & - & - \\
\hline $30-39$ & 2 & 984 & $.6(.1-2.3)$ & .35 & $.07-1.80$ & .21 \\
\hline $40-49$ & 1 & 189 & $.2(.1-1.5)$ & .10 & $.01-0.79$ & .02 \\
\hline $50-65$ & 2 & 1,323 & $3.4(.5-17.1)$ & .31 & $.05-1.70$ & .18 \\
\hline \multicolumn{7}{|l|}{ Employed } \\
\hline Yes & 14 & 7,228 & $1.4(.7-2.5)$ & 1 & - & - \\
\hline No & 1 & 646 & $2.4(.3-15.7)$ & 3.68 & $.50-26.80$ & .19 \\
\hline \multicolumn{7}{|l|}{ Educational attainment } \\
\hline$\leq$ Junior high school & 13 & 7,040 & $.4(.1-1.6)$ & 1 & - & - \\
\hline$\geq$ Senior high school & 2 & 834 & $2.2(1.1-4.0)$ & 5.59 & $1.19-26.21$ & .02 \\
\hline \multicolumn{7}{|l|}{ Number of children } \\
\hline 0 & 6 & 3,433 & $6.3(2.2-16.0)$ & 1 & - & - \\
\hline $1-2$ & 7 & 3,748 & $1.1(.4-2.7)$ & .16 & $.05-0.55$ & .00 \\
\hline$\geq 3$ & 2 & 693 & $.5(.1-2.1)$ & .08 & $.01-0.44$ & .00 \\
\hline \multicolumn{7}{|l|}{ Perinatal period } \\
\hline Pregnancy & 6 & 2,921 & $1.1(.3-2.8)$ & 1 & - & - \\
\hline Postpartum & 9 & 4,953 & $1.9(.9-3.7)$ & 4.11 & $1.00-16.78$ & .04 \\
\hline
\end{tabular}

Note: Analyses were performed of men who had a pregnant partner or in the first six months of their partners' postpartum $(N=534,965, n=997)$.

ternal perinatal stress, low educational attainment reduces the ability to cope with stress (Kubzansky, Kawachi, \& Sparrow, 1999), and may also reduce the opportunities for securing a better paid job.

Subsequent fathers were found to be less likely to experience severe psychological distress than first-time fathers. Philpott's et al. (2017) systematic review and Darwin's et al. (2017) study on fathers' mental health during the perinatal period lend do not support our findings. Darwin et al. (2017) observed that, although subsequent fathers may feel less stress because of the experience gained in the previous birth, they may also experience anticipatory anxiety concerning the new birth, and face new challenges, such as having to meet the needs of the new baby and its siblings. This aspect warrants further study.

As for our finding that there is an increase in the risk for psychological distress in the postpartum, compared to the prenatal period, this contradicts the evidence that pregnancy rather than the postpartum period is a period of higher stress in men in the transition to parenthood (Condon, Corkindale, \& Boyce, 2004). Differences in results could be explained by Schulz's (2016) longitudinal study, which included three measurement points in pregnancy and three in the postpartum, finding that levels of stress, depression, and anxiety vary within each period. Fathers' stress peaked just before and after the birth of the baby yet remained similar at other time points. After birth, depression peaked at 12 weeks and six months postpartum, and anxiety at 12 weeks postpartum. These findings point to the need for further longitudinal studies to understand the sources of stress and their effect on fathers' mental health along the perinatal period.

There is an almost total absence of studies on the reactions of fathers to childbirth and the impact to their mental health in Latin America. The present population study is the first of its kind in Mexico. Our findings suggest that Mexican fathers experience psychological distress in the perinatal period, which needs to be further addressed. Due to the nature of this survey, no other variables could be included to provide a more comprehensive view of paternal perinatal distress, such as the impact of fathers' involvement in childcare or sociodemographic variables during the perinatal period.

The strengths of this study are as follows: a. Findings are based on a population-based sample, which means that they can be extended to the general population of Mexican perinatal men, b. This is the first population study targeting perinatal risk for psychological distress in Mexican fathers. c. The measurement of psychological distress extends beyond the restrictive symptoms associated with depression so as to include anxiety and stress, and psychological and behavioral responses in a clinically meaningful way (Button et al., 2017); and d. The K6 scale is a valid instrument to distinguish community cases based on severity rather than purely on diagnosis (Kessler et al., 2002). 
Some of the main limitations that should be considered when interpreting these findings include the fact that a) This was a cross-sectional study, which does not allow predictions from pregnancy to be extrapolated to the postpartum period; b) The primary survey contained a long section on addictions, meaning that very few questions could be included on the remaining topics, such as a longer depression scale and certain relevant psychosocial predictors, which would have shed more light on paternal perinatal depression and distress, nor any possible confounding variables; c) The study does not account for the changes over time e.g., after birth than at six months postpartum that may occur within the perinatal period in psychological distress; d) It would have been interesting to investigate the differences by states, however, this analysis could not be carried out, since out of the total N (997), the $\mathrm{N}$ by state was very small. It is worth mentioning that the variation by states was very small (between $2 \%$ and $5 \%$ ).

Focusing on fathers' mental health during the perinatal period is important because of the suffering it causes them, as well as its impact on mothers and infants.

As mentioned earlier, mild psychological distress was suffered by a quarter of the fathers sampled. According to Kessler et al. (2003) and Condon et al. (2004) mild psychological distress involves maladaptive psychological responses and a range of psychological symptoms, such as anxiety, stress, and depression, which are clinically relevant and therefore warrant some form of minimum preventive or efficacious minimum interventions provided by health institutions. Some elements of a universal prevention policy should include offering sources of support and advice; tailor-made information for first-time fathers about perinatal depression (Baldwin, Malone, Sandall, \& Bick, 2018), infant care, their role as fathers, and potential relationship changes or strains that might be expected with their partners in routine care (Kumar, Oliffe, \& Kelly, 2018).

Only a small proportion of new fathers in the sample presented severe psychological distress; this suggests that these fathers were extremely likely to present a diagnosable mental disorder severe enough to cause functional limitations and require treatment, as Kessler et al. (2003) have noted. It has been observed that severe psychological distress leads to a progression towards externalizing behavior such as anger, breaking the law, and self-harm or suicide (Schulz, 2016). Consequently, it has been suggested that both mothers and fathers should be screened for psychological status, bearing in mind that men may display the aforementioned behavior and disorders rather than typical depression symptoms (Chhabra et al., 2020). Moreover, many men have negative attitudes towards help-seeking, and are therefore less likely to seek professional care due to masculine gender norms (Addis, 2008).

These findings suggest that it is necessary to go beyond the traditional approach in prenatal health care, which is centered on the mother and tends to overlook fathers.

\section{Funding}

The ENCODAT 2016-2017 survey was financed by the Comisión Nacional Contra las Adicciones (CONADIC), while the analysis and preparation of reports were undertaken by the US Department of State through the INL offices (SINLEC-17CA2011) as part of the Mérida Initiative.

\section{Conflict of interest}

The authors declare they have no conflicts of interest.

\section{Acknowledgements}

Thanks are due to those who worked with the Survey Unit of the Instituto Nacional de Psiquiatría for the dedication and commitment that made it possible to obtain this information.

\section{REFERENCES}

Addis, M. E. (2008). Gender and depression in men. Clinical Psychology Science and Practice, 15(3), 153-168. doi: 10.1111/j.1468-2850.2008.00125.x

Baldwin, S., Malone, M., Sandall, J., \& Bick, D. (2018). Mental health and wellbeing during the transition to fatherhood: a systematic review of first time fathers' experiences. JBI Database of Systematic Reviews and Implementation Reports, 16(11), 2118-2191. doi: 10.11124/JBISRIR-2017-003773

Banks, L. M., Kuper, H., \& Polack, S. (2017). Poverty and disability in low- and middle-income countries: A systematic review. PLoS One, 12(12), e0189996. doi: 10.1371/journal.pone.0189996

Bergström, M. (2013). Depressive symptoms in new first-time fathers: Associations with age, sociodemographic characteristics, and antenatal psychological wellbeing. Birth, 40(1), 32-38. doi: 10.1111/birt.12026

Borges, G., Medina-Mora, M. E., Wang, P. S., Lara, C., Berglund, P., \& Walters, E. (2006). Treatment and adequacy of treatment of mental disorders among respondents to the Mexico National Comorbidity Survey. American Journal of Psychiatry, 163(8), 1371-1378. doi: 10.1176/ajp.2006.163.8.1371

Button, S., Thornton, A., Lee, S., Shakespeare, J., \& Ayers, S. (2017). Seeking help for perinatal psychological distress: a meta-synthesis of women's experiences. British Journal of General Practice, 67(663), e692-e699. doi: 10.3399/ bjgp17X692549

Cameron, E. E., Sedov, I. D., \& Tomfohr-Madsen, L. M. (2016). Prevalence of paternal depression in pregnancy and the postpartum: An updated meta-analysis. Journal Affective Disorders, 206, 189-203. doi: 10.1016/j.jad.2016.07.044

Chhabra, J., McDermott, B., \& Li, W. (2020). Risk factors for paternal perinatal depression and anxiety: A systematic review and meta-analysis. Psychology of Men \& Masculinities, 21(4), 593-611. doi: 10.1037/men0000259

Cochran, S. V., \& Rabinowitz, F. E. (2000). Men and depression: Clinical and empirical perspectives (Practical resources for the mental health professional). Academic Press.

Condon, J. T., Corkindale, C. J., \& Boyce, P. (2004). The First-Time Fathers Study: A Prospective Study of the Mental Health and Wellbeing of Men during the Transition to Parenthood. Australian \& New Zealand Journal of Psychiatry, 38(1-2), 56-64. doi: 10.1177/000486740403800102

Darwin, Z., Galdas, P., Hinchliff, S., Littlewood, E., McMillan, D., McGowan, L., \& Gilbody S. (2017). Fathers' views and experiences of their own mental health during pregnancy and the first postnatal year: a qualitative interview study of men participating in the UK Born and Bred in Yorkshire (BaBY) cohort. BMC Pregnancy and childbirth, 17(1), 45. doi: 10.1186/s12884-017-1229-4

Falah-Hassani, K., Shiri, R., \& Dennis, C. L. (2017). The prevalence of antenatal and postnatal co-morbid anxiety and depression: a meta-analysis. Psychological Medicine, 47(12), 2041-2053. doi: 10.1017/S0033291717000617

Fisher, J., Cabral de Mello, M., Patel, V., Rahman, A., Tran, T., Holton, S., \& Holmes W. (2012). Prevalence and determinants of common perinatal mental disorders in women in low- and lower-middle-income countries: a systematic review. 
Bulletin of the World Health Organization, 90(2), 139-149. doi: 10.2471/ BLT.11.091850

Giallo, R., Cooklin, A., Wade, C., D’Esposito, F., \& Nicholson, J. M. (2014). Fathers' Postnatal Mental Health and Child Well-Being at Age Five: The Mediating Role of Parenting Behavior. Journal of Family Issues, 35(11), 1543-1562. doi: $10.1177 / 0192513 X 13477411$

Glasser, S., \& Lerner-Geva, L. (2019). Focus on fathers: paternal depression in the perinatal period. Perspectives in Public Health, 139(4), 195-198. doi: $10.1177 / 1757913918790597$

Goldberg, D. (1978). Manual of the General Health Questionnaire. NFER Publishing Company.

Goldberg, D. P., \& Hillier, V. F. (1979). A scaled version of the General Health Questionnaire. Psychological Medicine, 9(1), 139-145. doi: 10.1017/ S0033291700021644

Instituto Nacional de Estadística, Geografía e Informática (INEGI). (2015). Porcentaje de población que no posee nacionalidad mexicana (Porcentaje), 2015. México: INEGI. Retrieved from: https://www.inegi.org.mx/app/indicado res/?ind=6207019025\&tm=6\#divFV6207019025\#D6207019025 (Access date: April 26, 2021)

Kessler, R. C., Andrews, G., Colpe, L. J., Hiripi, E., Mroczek, D. K., Normand, S.-L. T., ... Zaslavsky, A. M.. (2002). Short screening scales to monitor population prevalences and trends in non-specific psychological distress. Psychological Medicine, 32(6), 959-976. doi: 10.1017/s0033291702006074

Kessler, R. C., Barker, P. R., Colpe, L. J., Epstein, J. F., Gfroerer, J. C., Hiripi, E., ... Zaslavsky, A. M. (2003). Screening for serious mental illness in the general population. Archives of General Psychiatry, 60(2), 184-189. doi: 10.1001/ archpsyc.60.2.184

Kessler, R. C., Green, J. G., Gruber, M. J., Sampson, N. A., Bromet, E., Cuitan, M., ... Zaslavsky, A. M. (2010). Screening for serious mental illness in the general population with the K6 screening scale: results from the WHO World Mental Health (WMH) survey initiative. International Journal of Methods in Psychiatric Research, 19(Suppl 1), 4-22. doi: 10.1002/mpr.310

Kubzansky, L. D., Kawachi, I., \& Sparrow, D. (1999). Socioeconomic status, hostility, and risk factor clustering in the normative aging study: Any help from the concept of allostatic load? Annals of Behavioral Medicine, 21(4), 330-338. doi: 10.1007/BF02895966

Kumar, S. V., Oliffe, J. L., \& Kelly, M. T. (2018). Promoting Postpartum Mental Health in Fathers: Recommendations for Nurse Practitioners. American Journal of Men's Health, 12(2), 221-228. doi: 10.1177/15579883177444712

Lara, M. A., Navarrete, L., \& Nieto, L. (2016). Prenatal predictors of postpartum depression and postpartum depressive symptoms in Mexican mothers: a longitudinal study. Archives of Women's Mental Health, 19(5), 825-834. doi: 10.1007/s00737-016-0623-7

Leach, L. S., Poyser, C., Cooklin, A. R., \& Giallo, R. (2016). Prevalence and course of anxiety disorders (and symptom levels) in men across the perinatal period: A systematic review. Journal of Affective Disorders, 190, 675-686. doi: 10.1016/j. jad.2015.09.063

Lovibond, S. H., \& Lovibond, P. F. (1995). Manual for the Depression Anxiety Stress Scales. 2nd ed. Sydney: Psychology Foundation of Australia.

McCoy, B. S. J. (2012). Postpartum Depression in Men. In M. G. Rojas Castillo (Ed.). Perinatal Depression, (pp. 163-176). E-Publishing Inc. Retrieved from http:// www.intechopen.com/books/perinatal-depression/postpartum-depression-inmen-
Morales, A., Catalán, A., \& Pérez, F. (2018). Los padres también se deprimen en el postparto: comprendiendo el fenómeno desde la voz de sus protagonistas. Polis (Santiago), 17(50), 161-181. doi: 10.4067/S0718-65682018000200161

Ocampo, R., Heinze, G., \& Ontiveros, M. P. (2007). Detección de depresión postparto en el Instituto Nacional de Perinatología. Psiquiatría, 23(3), 18-22.

O’Brien, A. P., McNeil, K. A., Fletcher, R., Conrad, A., Wilson, A. J., Jones, D., \& Chan S. W. (2017). New Fathers' Perinatal Depression and Anxiety-Treatment Options: An Integrative Review. American Journal of Men's Health, 11(4), 863876. doi: $10.1177 / 1557988316669047$

Paulson, J. F., \& Bazemore, S. D. (2010). Prenatal and postpartum depression in fathers and its association with maternal depression: A Meta-Analysis. JAMA, 303(19), 1961-1069. doi: 10.1001/jama.2010.605

Philpott, L. F., Leahy-Warren, P., FitzGerald, S., \& Savage, E. (2017). Stress in fathers in the perinatal period: A systematic review. Midwifery, 55, 113-127. doi: 10.1016/j.midw.2017.09.016

Philpott, L. F., Savage, E., Leahy-Warren, P., \& FitzGerald, S. (2020). Paternal perinatal depression: A narrative review. International Journal of Mens Social and Community Health, 3(1), e1-e15. doi: 10.22374/ijmsch.v3i1.22

Pinheiro, K. A., Coelho, F. M., Quevedo, L. de Á., Jansen, K., Souza, L. de M., Oses, J. P., ... Pinheiro, R. T. (2011). Paternal postpartum mood: bipolar episodes? Brazilian Journalof Psyquiatry, 33(3), 283-286. doi: 10.1590/s151644462011000300012

Pinheiro, R. T., Magalhães, P. V., Horta, B. L., Pinheiro, K. A., da Silva, R. A., \& Pinto, R. H. (2006). Is paternal postpartum depression associated with maternal postpartum depression? Population-based study in Brazil. Acta Psychiatrica Scandinavica, 113(3), 230-232. doi: 10.1111/j.1600-0447.2005.00708.x

Ramírez Rodríguez, J. C., \& Cervantes Ríos, J. C. (2013). Los hombres en México: veredas recorridas y por andar. Una mirada a los estudios de género de los hombres, las masculinidades. México: Universidad de Guadalajara.

Schulz, A. (2016). Fatherhood and Psychological Distress: Paternal Depression, Anxiety and Stress in the Perinatal Period, in School of Psychology. Australia: Deakin University.

Skari, H., Skreden, M., Malt, U. F., Dalholt, M., Ostensen, A. B., Egeland, T., \& Emblem, R. (2002). Comparative levels of psychological distress, stress symptoms, depression and anxiety after childbirth—a prospective populationbased study of mothers and fathers. BJOG: An International Journal of Obstetrics and Gynaecology, 109(10), 1154-1163. doi: 10.1111/j.14710528.2002.00468.x

Tena, O. (2014). Malestares laborales y condición masculina. Reflexiones en torno a la flexibilidad laboral. In J. G. Figueroa, (Coord.). Políticas públicas y la experiencia de ser hombre. Paternidad, espacios laborales, salud y educación. México: El Colegio de México.

Vargas, T. B., Villamil, S. V., Rodríguez, E. C., Pérez, R. J., \& Cortés, S. (2011). Validación de la escala Kessler 10 (K-10) en la detección de depresión y ansiedad en el primer nivel de atención. Propiedades psicométricas. Salud Mental, 34(4), 323-331.

Vismara, L., Rollè, L., Agostini, F., Sechi, C., Fenaroli, V., Molgora, S., ... Tambelli, R. (2016). Perinatal Parenting Stress, Anxiety, and Depression Outcomes in First-Time Mothers and Fathers: A 3- to 6-Months Postpartum Follow-Up Study. Frontiers in Psychology, 7, 938. doi: 10.3389/fpsyg.2016.00938

Wall, G., \& Arnold, S. (2007). How involved is involved fathering?:An exploration of the contemporary culture of fatherhood. Gender \& Society, 21(4), 508-527. doi: $10.1177 / 0891243207304973$ 